\title{
Intraoperative End-Tidal Carbon Dioxide Concentrations: What Is the Target?
}

\author{
Megan Way and Gary E. Hill \\ Department of Anesthesiology and Pain Management, The University of Texas Southwestern Medical Center at Dallas, \\ Dallas, TX 75390-9068, USA \\ Correspondence should be addressed to Gary E. Hill, hill8430@sbcglobal.net
}

Received 17 July 2011; Accepted 25 August 2011

Academic Editor: Mukesh Tripathi

Copyright ( 2011 M. Way and G. E. Hill. This is an open access article distributed under the Creative Commons Attribution License, which permits unrestricted use, distribution, and reproduction in any medium, provided the original work is properly cited.

Recent publications suggest that target end-tidal carbon dioxide concentrations should be higher than values currently considered as acceptable. This paper presents evidence that end-tidal carbon dioxide values higher than concentrations that are currently targeted result in improved patient outcomes and are associated with a reduced incidence of postoperative complications.

Since the reports of benefits of permissive hypercapnia in the critical care literature [1], the current practice of maintaining mild hypocapnia (i.e., end-tidal carbon dioxide $\left[\mathrm{ETCO}_{2}\right]$ values between 30 and $35 \mathrm{mmHg}$ ) is being questioned. This paper will discuss the concerns with mild hyperventilation and hypocapnia and will propose maintenance of higher $\mathrm{ETCO}_{2}$ values based on recent literature. Also, the importance of the relationship between cardiac output and $\mathrm{ETCO}_{2}$, in particular within the context of low cardiac output states, including weaning from cardiopulmonary bypass ( $\mathrm{CPB})$, will be discussed.

In an effort to determine the origin for the current practice of mild hypocapnia, a literature search with the key words intraoperative, general anesthesia, hypocapnia, hypocarbia, or hyperventilation was performed. However, it failed to find peer-reviewed articles describing well-defined benefits of mild hypocapnia during general anesthesia. The use of mild hypocapnia may have been introduced because of the concerns of hypercapnia-related hypertension and tachycardia that may increase myocardial $\mathrm{O}_{2}$ demand, which may lead to myocardial ischemia and infarction [2]. Other proposed benefits of intraoperative hypocapnia include reduction in the need for muscle relaxants as well as reduced hypnotic requirements. However, there is no good evidence for such claims. Despite the lack of peer-reviewed data, mild hypocapnia remains accepted in clinical practice.
Classic scientific publications by Seymour Kety and Carl Schmidt $[3,4]$ in the 1940s demonstrated the wellknown curvilinear increase of cerebral blood flow (CBF) with increasing arterial carbon dioxide $\left(\mathrm{PaCO}_{2}\right)$ concentrations, secondary to reduced cerebral vascular resistance, as well as increases in cardiac output (CO) and systemic arterial blood pressure (ABP) caused by hypercapnia. Hypocapnia, on the other hand, caused the opposite effects: reduction of $\mathrm{CBF}$ and an increase in cerebral oxygen $\left(\mathrm{O}_{2}\right)$ consumption, secondary to cerebral vasoconstriction and reduced CO. These foundational publications were followed closely with another classic paper by Cournand et al. [5] demonstrating that a reduction of $\mathrm{CO}$ occurred following the application of positive pressure ventilation. Thus, it has been well established for over 60 years that positive pressure ventilation with ensuing hypocarbia has the undesirable consequences of the reduction of $\mathrm{CO}$, mean arterial blood pressure and CBF.

The detrimental effects of hyperventilation and hypocapnia are many. Initiation of hyperventilation immediately after induction of anesthesia, which causes vasodilatation and relative hypovolemia, may cause significant reduction in venous return, underfilling of the right heart, and subsequent reduction of $\mathrm{CO}$ and $\mathrm{ABP}$ [6]. In addition, hypocapnia may cause prolongation of the QT interval and cardiac arrhythmias [7]. Other effects of hypocapnia include increases in lung microvascular permeability, decreased lung 
compliance (due to bronchoconstriction), increased intrapulmonary shunt fraction caused by inhibition of hypoxic pulmonary vasoconstriction, and leftward shift of the oxyhemoglobin dissociation curve, as well as worsened outcome after acute head injury and cardiopulmonary resuscitation [8].

Otherwise healthy patients subjected to intraoperative hypocapnia $\left(\mathrm{PaCO}_{2}=24 \mathrm{mmHg}\right)$ during routine general anesthesia demonstrate cognitive dysfunction for several days postoperatively [9]. A control group maintained with $\mathrm{PaCO} 2$ levels greater than $24 \mathrm{mmHg}$ did not demonstrate any signs of cognitive dysfunction. Hovorka [10] reported in female patients that the hypercapnic group $\left(\mathrm{PaCO}_{2}=\right.$ $54 \mathrm{mmHg}$ ) was found to have better cognitive function scores when compared to both a normocapnic group $\left(\mathrm{PaCO}_{2}=\right.$ $40 \mathrm{mmHg})$ and two hypocapnic groups $\left(\mathrm{PaCO}_{2}=28\right.$ in patients older than $60 \mathrm{yrs}$ and $22 \mathrm{mmHg}$ in patients under $46 \mathrm{yrs}$ of age). Also, the normocapnic group had better cognitive function scores than both hypocapnic groups. Even short duration hypocapnia during cesarean section has negative effects on the fetus, including decreased fetal $\mathrm{PaO}_{2}$ levels, increased base deficit, and lower Apgar scores [8].

Because hypocarbia is known to reduce CBF, Rosner et al. [11] have focused on cerebral perfusion pressure management of traumatic brain injury (TBI) rather than standard hyperventilation management and have reported favorable outcomes. Despite current guidelines recommending against it [12], deliberate hyperventilation continues to be routinely used for TBI. In fact, over one-third neurosurgeons and half emergency physicians still utilize hyperventilation for ICP control after TBI.

In contrast to the detrimental effects of hypocapnia, mild hypercapnia has number of benefits. Mild respiratory acidosis demonstrates a protective effect against organ injury, and targeting a normal (or lower than normal) $\mathrm{PaCO}_{2}$ may be injurious [13]. Mild hypercapnia can improve tissue oxygenation through improved tissue perfusion resulting from increased $\mathrm{CO}$ and vasodilatation as well as increased $\mathrm{O}_{2}$ off-loading from the shift of the oxyhemoglobin dissociation curve to the right. Akça et al. [14] reported increased subcutaneous tissue $\mathrm{O}_{2}$ tension $\left(\mathrm{PsqO}_{2}\right)$ measured in the upper arm with mild hypercapnia. Their data demonstrated a linear increase of $\mathrm{PsqO}_{2}$ with increasing $\mathrm{ETCO}_{2}$, with the greatest increase of $\mathrm{PsqO}_{2}$ at an $\mathrm{ETCO}_{2}$ of $60 \mathrm{mmHg}$. Since $\mathrm{PsqO}_{2}$ is significantly correlated with the risk of surgical infections, with higher $\mathrm{PsqO}_{2}$ resulting in lower infection rates, this implies an important benefit of mild hypercapnia in reducing postoperative infection rates. Mild hypercapnia similarly improves $\mathrm{PsqO}_{2}$ in the morbidly obese [15]. Mild hypercapnia $\left(\mathrm{ETCO}_{2} 50 \mathrm{mmHg}\right)$ along with increased inhaled $\mathrm{O}_{2}$ concentration $(80 \%)$ resulted in increased subcutaneous and colonic tissue $\mathrm{O}_{2}$ tensions in patients during colon resection [16], implying such therapy may prove to be beneficial in reducing infection rates and a more rapid return to normal bowel function.

Several investigators have reported improved lung function (e.g., reduced intrapulmonary shunt) in patients with respiratory distress syndrome using a protective ventilatory strategy (i.e., permissive hypercapnia, $\mathrm{PaCO}_{2}$ of $\pm 50 \mathrm{mmHg}$ ) when compared to control groups managed in a traditional manner (i.e., $\mathrm{PaCO}_{2}$ of $\pm 35 \mathrm{mmHg}$ ) [1]. Respiratory acidosis (hypercapnia) attenuates or dampens inflammation caused by established bacterial pneumonia [17], ischemiareperfusion, and endotoxin-induced lung injury.

It has been well established that large tidal volume ventilation causes a stretch type of injury (volutrauma) resulting in lung inflammation characterized by proinflammatory cytokine release, airway edema, and increased extravascular lung water. Lung injury, measured by increased lung weight and hemorrhage scores, is also reduced by decreased respiratory frequency (ventilatory rate) in animals [18]. While the relationship between proinflammatory cytokine release and ventilator-induced lung injury remains to be clearly defined [19], there seems to be a general consensus of opinion that proinflammatory cytokines may be involved in positive pressure ventilation-induced lung injury.

Sakata et al. [20] have utilized hypercapnia (achieved by rebreathing exhaled $\mathrm{CO} 2$ ) in conjunction with hyperventilation to shorten recovery times following sevoflurane and desflurane anesthesia.

While mild hypercapnia has well-defined clinical benefits, it must be avoided in certain clinical scenarios. Clearly, mild hypercapnia would further exacerbate elevated intracranial pressure. In addition, hypercapnia may lead to significant diaphragm muscle dysfunction/fatigue [21]. Furthermore, hypercapnic respiratory acidosis may cause increased difficulty in the reversal of nondepolarizing neuromuscular blocking agents by neostigmine [22]. Interestingly, an author of one of the original reports on the negative consequences of hypercapnia [23] published a creative and unique paper investigating the mechanism of brain injury found after mountain climbing to extreme altitudes [24]. The surprising results demonstrated that it was not hypoxemia that caused brain injury but hypocapnic-induced reduction of $\mathrm{CBF}$ as the primary mechanism of CNS injury after climb, dramatizing the serious negative consequences of hypocapnia on normal brain function.

Falk et al. [25] were the first to report that $\mathrm{ETCO}_{2}$ could be used to predict outcomes following cardiopulmonary resuscitation (CPR). Their data demonstrated rapidly increasing (within 30 seconds following initiation of CPR) $\mathrm{ETCO}_{2}$ was predictive of survival, while continuing low levels of $\mathrm{ETCO}_{2}$ predicted death. Similarly, Levine et al. [26] found that $\mathrm{ETCO}_{2}$ levels of $32.8+7.4 \mathrm{mmHg}$ predicted survival while low $\mathrm{ETCO}_{2}$ levels $(4.4+2.9 \mathrm{mmHg})$ predicted death following $20 \mathrm{~min}$ of CPR. Levine et al. [26] also found that an $\mathrm{ETCO}_{2}$ level of $10 \mathrm{mmHg}$ or less was $100 \%$ accurate when predicting death following $20 \mathrm{~min}$ of CPR. Other clinical scenarios characterized by low cardiac output (hemorrhage or weaning from cardiopulmonary bypass $(\mathrm{CPB})$ ) have demonstrated a similar direct correlation between cardiac output and $\mathrm{ETCO}_{2}$. Dubin et al. [27] demonstrated a direct linear correlation between $\mathrm{CO}$ and $\mathrm{ETCO}_{2}$ during progressive hemorrhage in an anesthetized dog model. In humans with normal preoperative lung function, Maslow et al. [28] reported a significant direct correlation between $\mathrm{CO}$ and $\mathrm{ETCO}_{2}$ during weaning from $\mathrm{CPB}$. Their data demonstrated that when $\mathrm{ETCO}_{2}$ was greater than $30 \mathrm{mmHg}$, 
$\mathrm{CO}$ was greater than $4.0 \mathrm{~L} / \mathrm{min}$, and when $\mathrm{ETCO}_{2}$ was greater than $34 \mathrm{mmHg}$, CO was greater than $5 \mathrm{~L} / \mathrm{min}$.

Similar findings were reported by Feng and singh. [29] who found that separation from CPB was successful in patients whose $\mathrm{ETCO}_{2}$ was consistently near or greater than $30 \mathrm{mmHg}$.

In conclusion, the dogma of maintaining $\mathrm{ETCO}_{2}$ values between 30 and $35 \mathrm{mmHg}$ is without scientific merit and needs to be revisited. In fact, hypocapnia, and the hyperventilation required to achieve it, is clearly not benign. On the other hand, mild hypercapnia $\left(\mathrm{ETCO}_{2}\right.$ values around $40 \mathrm{mmHg}$ or higher, but with the caveats as previously described) is beneficial and should come to be accepted as the standard of care.

\section{References}

[1] M. B. P. Amato, C. S. V. Barbas, D. M. Medeiros et al., "Effect of a protective-ventilation strategy on mortality in the acute respiratory distress syndrome," New England Journal of Medicine, vol. 338, no. 6, pp. 347-354, 1998.

[2] A. Mas, P. Saura, D. Joseph et al., "Effect of acute moderate changes in $\mathrm{PaCO}_{2}$ on global hemodynamics and gastric perfusion," Critical Care Medicine, vol. 28, no. 2, pp. 360-365, 2000.

[3] S. S. Kety and C. F. Schmidt, "The effects of active and passive hyperventilation on cerebral blood flow, cerebral oxygen consumption, cardiac output, and blood pressure of normal young men," Journal of Clinical Investigation, vol. 25, pp. 107119, 1946.

[4] S. S. Kety and C. F. Schmidt, "The effects of altered arterial tensions of carbon dioxide and oxygen on cerebral blood flow and cerebral oxygen consumption of normal young men," Journal of Clinical Investigation, vol. 27, pp. 484-492, 1948.

[5] A. Cournand, H. L. Motley, and L. Werko, "Physiological studies of the effects of intermittent positive pressure breathing on cardiac output in man," American Journal of Physiology, vol. 152, pp. 162-173, 1948.

[6] M. R. Pinsky, "Cardiovascular effects of ventilatory support and withdrawl," Anesthesia and Analgesia, vol. 79, pp. 567-76, 1994.

[7] K. C. Wong, P. G. Schafer, and J. R. Schultz, "Hypokalemia and anesthetic implications," Anesthesia and Analgesia, vol. 77, no. 6, pp. 1238-1260, 1993.

[8] J. G. Laffey and B. P. Kavanagh, "Medical progress: hypocapnia," New England Journal of Medicine, vol. 347, no. 1, pp. 4353, 2002.

[9] S. B. Wollman and L. R. Orkin, "Postoperative human reaction time and hypocarbia during anaesthesia," British Journal of Anaesthesia, vol. 40, no. 12, pp. 920-926, 1968.

[10] J. Hovorka, "Carbon dioxide homeostasis and recovery after general anaesthesia," Acta Anaesthesiologica Scandinavica, vol. 26, no. 5, pp. 498-504, 1982.

[11] M. J. Rosner, S. D. Rosner, and A. H. Johnson, "Cerebral perfusion pressure: management protocol and clinical results," Journal of Neurosurgery, vol. 83, no. 6, pp. 949-962, 1995.

[12] D. W. Marion and T. P. Spiegel, "Changes in the management of severe traumatic brain injury: 1991-1997," Critical Care Medicine, vol. 28, no. 1, pp. 16-18, 2000.

[13] J. G. Laffey and B. P. Kavanagh, "Carbon dioxide and the critically ill-Too little of a good thing?" The Lancet, vol. 354, no. 9186, pp. 1283-1286, 1999.
[14] O. Akça, A. G. Doufas, N. Morioka, S. Iscoe, J. Fisher, and D. I. Sessler, "Hypercapnia improves tissue oxygenation," Anesthesiology, vol. 97, no. 4, pp. 801-806, 2002.

[15] H. Hager, D. Reddy, G. Mandadi et al., "Hypercapnia improves tissue oxygenation in morbidly obese surgical patients," Anesthesia and Analgesia, vol. 103, no. 3, pp. 677-681, 2006.

[16] E. Fleischmann, F. Herbst, A. Kugener et al., "Mild hypercapnia increases subcutaneous and colonic oxygen tension in patients given $80 \%$ inspired oxygen during abdominal surgery," Anesthesiology, vol. 104, no. 5, pp. 944-949, 2006.

[17] M. N. Chonghaile, B. D. Higgins, J. Costello et al., "Hypercapnic acidosis attenuates lung injury induced by established bacterial pneumonia," Anesthesiology, vol. 109, no. 5, pp. 837$848,2008$.

[18] J. R. Hotchkiss, L. Blanch, G. Murias et al., "Effects of decreased respiratory frequency on ventilator-induced lung injury," American Journal of Respiratory and Critical Care Medicine, vol. 161, no. 2, pp. 463-468, 2000.

[19] D. Dreyfuss and J. J. Rouby, "Mechanical ventilation-induced lung release of cytokines: a key for the future or Pandora's box?" Anesthesiology, vol. 101, no. 1, pp. 1-3, 2004.

[20] D. J. Sakata, N. A. Gopalakrishnan, J. A. Orr, J. L. White, and D. R. Westenskow, "Rapid recovery from sevoflurane and desflurane with hypercapnia and hyperventilation," Anesthesia and Analgesia, vol. 105, no. 1, pp. 79-82, 2007.

[21] S. Jaber, B. Jung, M. Sebbane et al., "Alteration of the piglet diaphragm contractility in vivo and its recovery after acute hypercapnia," Anesthesiology, vol. 108, no. 4, pp. 651-658, 2008.

[22] K. Wirtavuori, M. Salmenpera, and T. Tammisto, "Effect of hypocarbia and hypercarbia on the antagonism of pancuronium-induced neuromuscular blockade with neostigmine in man," British Journal of Anaesthesia, vol. 54, no. 1, pp. 57-61, 1982.

[23] B. C. Morgan, E. W. Crawford, T. F. Hornbein, W. E. Martin, and W. G. Guntheroth, "Hemodynamic effects of changes in arterial carbon dioxide tension during intermittent positive pressure ventilation," Anesthesiology, vol. 28, no. 5, pp. 866873, 1967.

[24] T. F. Hornbein, B. D. Townes, R. B. Schoene, J. R. Sutton, and C. S. Houston, "The cost to the central nervous system of climbing to extremely high altitude," New England Journal of Medicine, vol. 321, no. 25, pp. 1714-1719, 1989.

[25] J. L. Falk, E. C. Rackow, and M. H. Weil, "End-tidal carbon dioxide concentration during cardiopulmonary resuscitation," New England Journal of Medicine, vol. 318, no. 10, pp. 607-611, 1988.

[26] R. L. Levine, M. A. Wayne, and C. C. Miller, "End-tidal carbon dioxide and outcome of out-of-hospital cardiac arrest," New England Journal of Medicine, vol. 337, no. 5, pp. 301-306, 1997.

[27] A. Dubin, C. Silva, G. Calvo et al., "End-tidal $\mathrm{CO}_{2}$ pressure in the monitoring of cardiac output during canine hemorrhagic shock," Journal of Critical Care, vol. 5, no. 1, pp. 42-46, 1990.

[28] A. Maslow, G. Stearns, A. Bert et al., "Monitoring end-tidal carbon dioxide during weaning from cardiopulmonary bypass in patients without significant lung disease," Anesthesia and Analgesia, vol. 92, no. 2, pp. 306-313, 2001.

[29] W. C. Feng and A. K. Singh, "Intraoperative use of end-tidal carbon dioxide tension to assess cardiac output," Journal of Thoracic and Cardiovascular Surgery, vol. 108, no. 5, pp. 991992, 1994. 


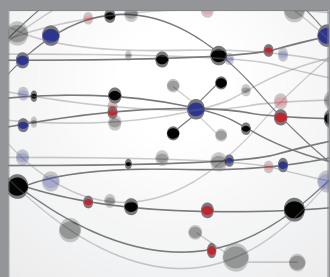

The Scientific World Journal
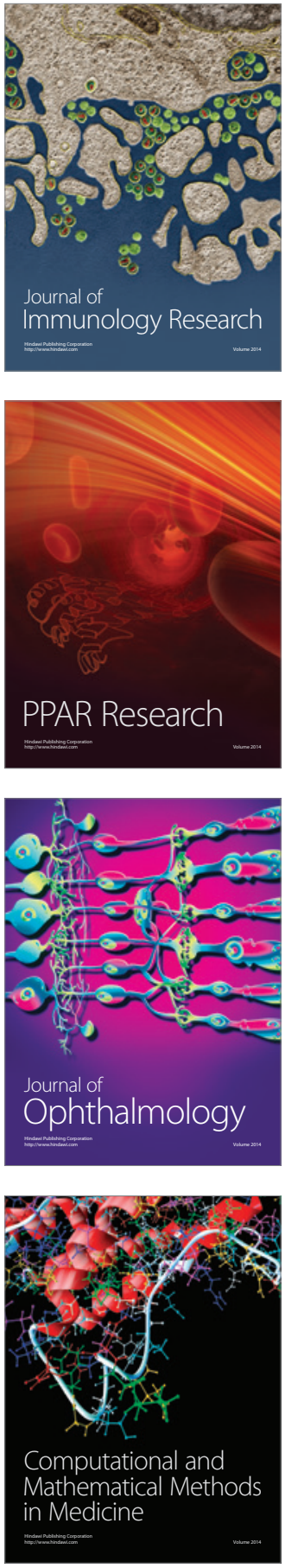

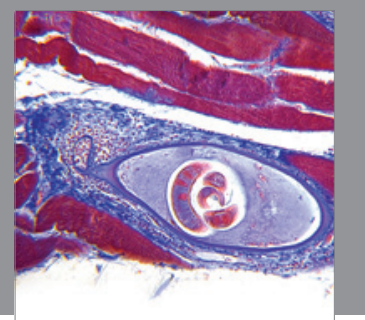

Gastroenterology

Research and Practice
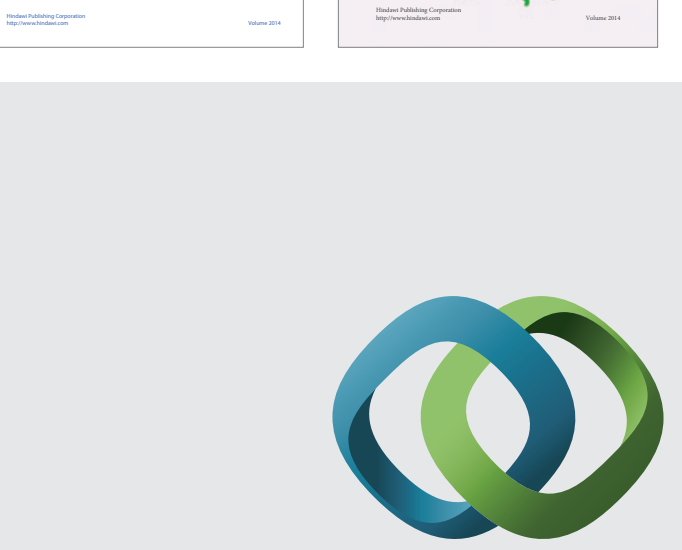

\section{Hindawi}

Submit your manuscripts at

http://www.hindawi.com
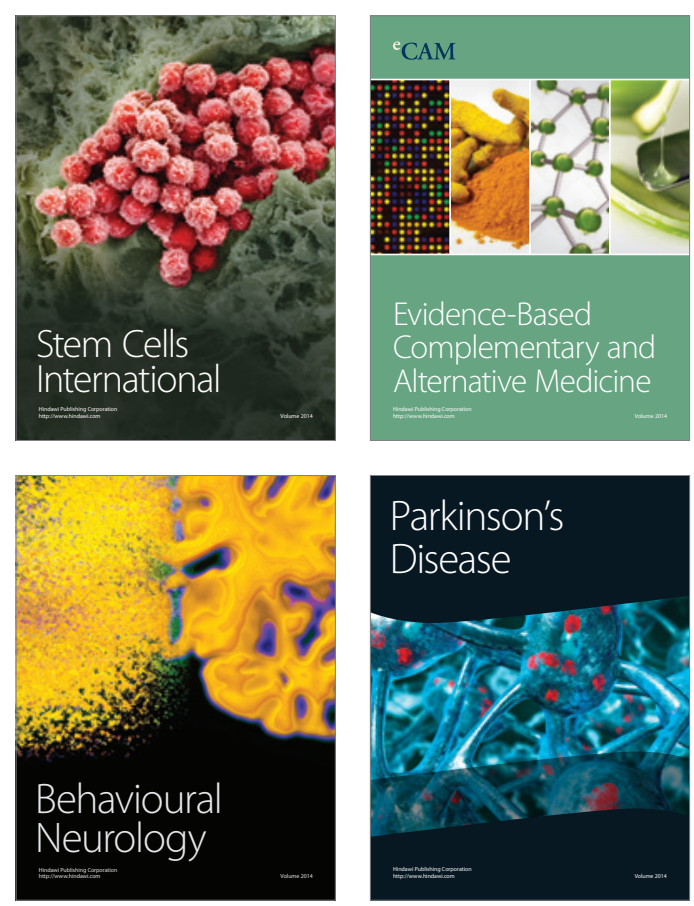

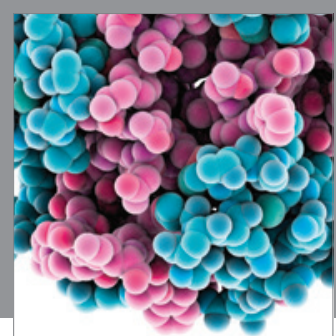

Journal of
Diabetes Research

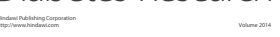

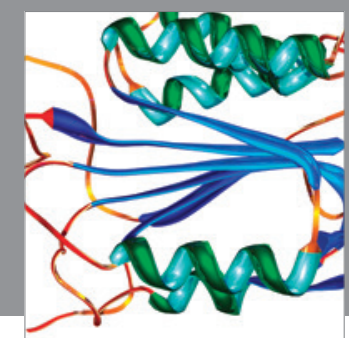

Disease Markers
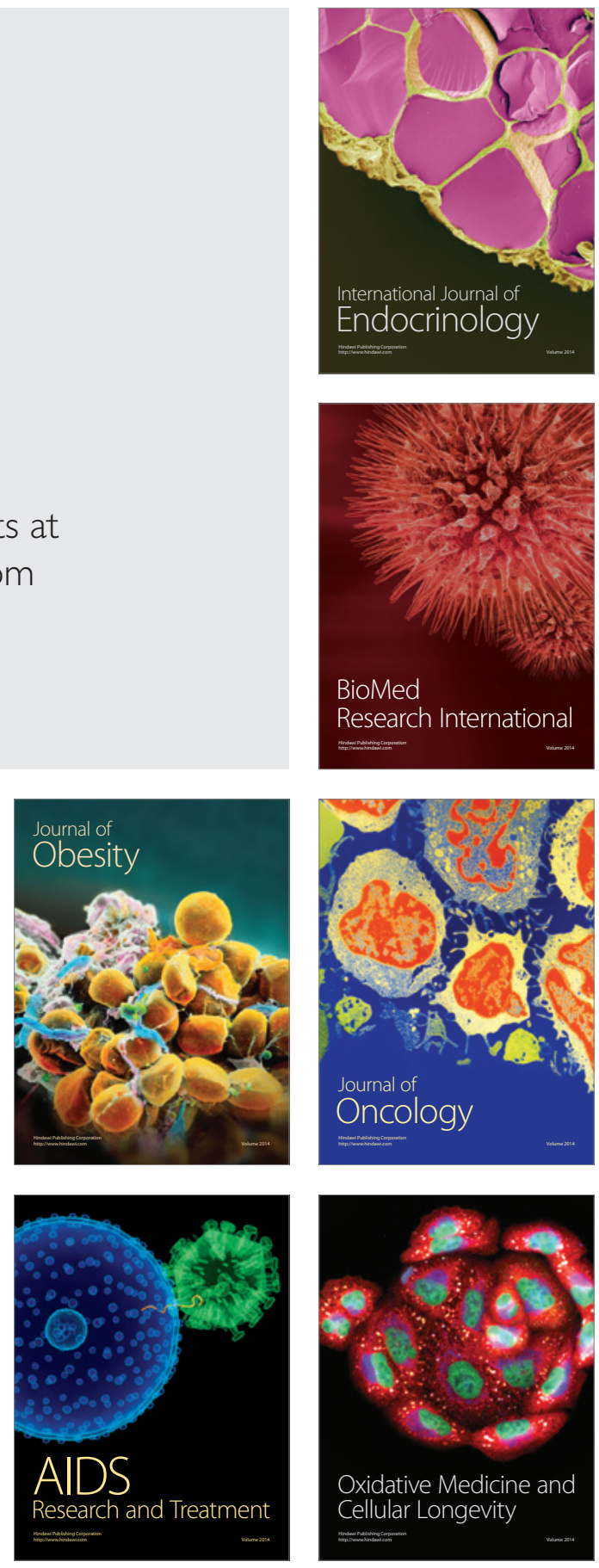